\title{
INTERNISMO DE RAZÕES E A CONCEPÇÃO PROCEDIMENTAL DE DELIBERAÇÃO CORRETA ${ }^{1}$
}

\author{
Tiaraju Andreazza (Unisinos) ${ }^{2}$ \\ tiaraju.andreazza@gmail.com
}

Resumo: $O$ objetivo deste artigo é discutir a teoria de razões para ação defendida por Bernard Williams. Após apresentar os seus principais conceitos (condição internista, dimensões explanatória e deliberativa, razões internas) e identificar o argumento que é oferecido em seu favor e contra posições alternativas, analiso a objeção de que a cogência do argumento depende da aceitação de uma concepção procedimental de deliberação correta que Williams teria assumido, sem argumentar, como verdadeira. Defendo que essa objeção é falsa porque é possível encontrar nos seus textos um argumento suplementar justificando a sua preferência por uma concepção procedimental.

Palavras-chave: Razões; Dimensão Explanatória; Dimensão Deliberativa. Concepção Procedimental.

\section{CONSIDERAÇÕES INICIAIS}

O prédio está em chamas e João está nele. Desorientado pela fumaça, pelo calor e pelo desespero das pessoas ao seu redor, João permanece sentado à sua mesa e em estado de choque. Ao final do corredor há uma porta que leva a uma saída de emergência. Se João não sair agora ele provavelmente morrerá asfixiado pela fumaça. Se ele sair, conseguirá escapar em segurança e ileso. O que João tem

\footnotetext{
${ }^{1}$ Recebido em: 11-04-2015/Aceito: 21-12-2015/Publicado on-line: 06-03-2016.

${ }^{2}$ Tiaraju Andreazza é Doutorando do Programa de Pós-Graduação em Filosofia da Universidade do Vale dos Sinos, São Leopoldo, RGS, Brasil.
} 
razão para fazer? Parece verdadeiro responder que o $(\mathrm{p})$ fato de que o prédio está em chamas é uma razão para (a) João, que (c) morrerá asfixiado se permanecer imóvel, $(\phi)$ se levantar, correr em direção à saída de emergência e sair o mais rápido possível do prédio. Esse enunciado estabelece uma relação normativa quadripartida $R(\mathrm{p}, \mathrm{a}, \mathrm{c}, \phi)$ entre um fato, um agente, um conjunto de circunstâncias e uma ação, uma relação tal em que um fato de alguma forma recomenda um certo curso de ação para João ${ }^{3}$.

Agora imagine que alguém afirme que o fato de que o prédio está em chamas é uma razão para João se levantar, tirar a roupa e correr em direção ao fogo. Essa sentença parece claramente falsa. Mas por que ela é falsa? Como nós podemos distinguir sentenças verdadeiras sobre as razões de João de sentenças falsas? $\bigcirc$ cenário filosófico das últimas décadas ofereceu diferentes respostas para essa pergunta. $\mathrm{O}$ internismo de razões, como a denominarei neste artigo, é a teoria oferecida por Williams para explicar o que é para um fato ser uma razão para alguém fazer algo e responder a essa pergunta. Ela defende que para avaliar se um enunciado sobre as razões de João é verdadeiro nós devemos levar em conta o que está no conjunto motivacional subjetivo (motivacional subjective set) de João. $\mathrm{O}$ meu objetivo neste artigo é discutir essa posição, buscando identificar o argumento que

\footnotetext{
${ }^{3}$ Recentemente filósofos estão debruçando-se na análise de enunciados do tipo "S tem uma razão para fazer $\phi$ ". Não há unanimidade em como entender esses enunciados. A caracterização adotada neste artigo é oferecida por Scanlon. Ela explica que enunciados de razões estabelecem uma relação normativa entre quatro termos, a saber, um fato, um agente, um conjunto de circunstâncias e uma ação $(2014,31)$. Essa análise parece ser uma sofisticação da análise de Schroeder, de acordo com a qual enunciados de razão estabelecem uma relação entre três termos, a saber, um fato, um agente e uma ação $(2007,17)$. Divergindo de Scanlon e Schroeder, Skorupski entende que se trata de uma relação entre cinco termos: um fato, um tempo $t$, um nível de força da razão, um agente e uma ação $(2010,37)$. Parece que os termos a mais que a análise de Skoruspki acrescenta são abrangidos pelo termo "conjunto de circunstâncias" da análise de Scanlon - que é, por esse motivo, uma análise mais elegante.
} 
Williams oferece em seu favor e uma objeção particular que pode ser direcionada contra ele ${ }^{4}$.

Para tanto, divido o artigo em seis seções. Nas três primeiras esclarecei os conceitos fundamentais da posição defendida por Williams: a condição internista, as dimensões explanatória e deliberativa de razões normativas e o conceito de razão normativa. Na quarta seção identificarei o argumento que é oferecido em favor dessa posição. Como ficará claro, esse argumento depende da aceitação de uma certa concepção procedimental de deliberação correta. A quinta seção caracteriza essa concepção e apresenta a objeção de que Williams estaria simplesmente a assumindo como verdadeira sem considerar a viabilidade de concepções alternativas. Contrariamente a essa objeção, na sexta seção defenderei que é possível encontrar nos escritos de Williams um argumento suplementar em favor de uma concepção procedimental.

\section{A CONDIÇÃO INTERNISTA}

O internismo de razões estipula que o enunciado "o fato de que o prédio está em chamas é uma razão para João sair do prédio" é um enunciado verdadeiro sobre as razões de João somente se a condição internista - como a denominarei a partir de agora - for satisfeita. Ao longo de seus artigos sobre o tema, Williams oferece pelo menos quatro formulações dessa condição. No que segue, essas quatro formulações serão discutidas na ordem cronológica em que foram publicadas.

\footnotetext{
${ }^{4}$ Williams articula e defende o internismo de razões nos seguintes artigos: "Internal and External Reasons" (originalmente publicado em 1980, republicado em 1981), "Internal Reasons and the Obscurity of Blame" (originalmente publicado em 1989, republicado em 1995a), "Replies" (1995b) e "Postscript: Some Further Notes on Internal and External Reasons" (2001). Os dois primeiros artigos serão sempre citados na edição republicada.
} 
Começo pela primeira, apresentada em "Internal and External Reasons" (a cito com modificações necessárias para o caso de João):

Condição internista (1): João tem uma razão para sair do prédio somente se João tem algum desejo que seria satisfeito pela realização dessa ação... Ou algum desejo que João acredita que seria satisfeito pela realização dessa ação ${ }^{5}$.

(1) estipula que toda razão para João tem de estar em alguma relação com algum fato motivacional a respeito de João. (1) menciona desejos, um termo que é utilizado por Williams em um sentido liberal para se referir a qualquer elemento que componha o que ele chama de o conjunto motivacional subjetivo de João. Esse conjunto é composto por suas disposições de avaliação, padrões de emoção racional, lealdades pessoais, planos, crenças e comprometimentos em geral (WILLIAMS, 1981, 105) - o seu uso da palavra desejo é tão liberal que até mesmo a crença de João de que ele tem uma razão para sair do prédio conta como um de seus "desejos" ${ }^{6}$. A tese internista básica é de que é falso atribuir uma razão a João quando

\footnotetext{
5 "A has a reason to $\phi$ iff A has some desire the satisfaction of which will be served by his $\phi$-ing. Alternatively, we might say... some desire, the satisfaction of which A believes will be served by his $\phi$-ing" (WILLIAMS, 1981, 101).

${ }^{6}$ Williams usa a palavra "desejo" (desire) em um sentido técnico próprio para se referir a qualquer elemento do conjunto motivacional do agente que possa tornar verdadeiro ou falso um enunciado de razões a respeito desse agente. Quando Williams discute o exemplo de Owen Wingrave ele aceita que uma posição externista poderia explicar a ação de Owen para se alistar ao exército apelando unicamente para o fato motivacional de que Owen acredita que tem uma razão para se alistar ao exército: "Does believing that a particular consideration is a reason to act in a particular way provide, or indeed consitute, a motivation to act? If it does not, then we are no futher on. Let us grant that it does - this claim indeed seems plausible, so long at least as the connexion between such beliefs and the dispositions to act is not tightened to that unnecessary degree which excludes akrasia" (WILLIAMS, 1981, 107). Nesse caso, a crença de Owen de que ele tem uma razão é um dos desejos do seu conjunto motivacional. Finlay (2011) analisa extensivamente como esse uso não-ortodoxo de "desejo", em que comprometimentos normativos e disposições para agir contam como desejos (WILLIAMS 1981, 105), invalida algumas interpretações "humeanas" da sua posição, como a interpretação popularizada por Korsgaard (1996).
} 
não há uma conexão entre essa razão e algo no seu conjunto motivacional. Considerando o caso do incêndio, é natural supor que João tem planos para o futuro e um genuíno interesse em viver, e, portanto, podemos explicar que ele tem uma razão para sair do prédio de acordo com (1) porque não saindo do prédio ele morreria asfixiado, frustrando o seu interesse de viver e de realizar os seus planos para o futuro.

(1), porém, parece inclusiva demais. Imagine que João tenha ido à cafeteria e pedido um café sem açúcar em virtude da sua diabetes. Por engano, e sem que ele soubesse, a garçonete lhe trouxe um café com açúcar, que João bebeu. Ele tinha razão para bebê-lo? ${ }^{7}$ Nós podemos muito bem dizer que João tinha uma razão para beber o café, nomeadamente, ele desejava no momento ter uma xícara de café e acreditava que a garçonete havia trazido o café tal como ele havia pedido. (1) parece autorizar essa atribuição de razão, pois ao beber o café João satisfez o desejo de beber um café, um desejo que fazia parte do seu conjunto motivacional no momento em que ele agiu. Não obstante, parece haver algo de errado nesse resultado e, por implicação, com (1).

O próprio Williams faz duas correções a essa formulação. A primeira é a seguinte: um membro $p$ do conjunto motivacional de João não fornece uma razão para João quando a sua existência é dependente de uma crença falsa, ou $p$ não fornece uma razão para João fazer $\phi$ quando a crença de João de que a realização de $\phi$ é relevante para a promoção de p é falsa (WILLIAMS 1981, 103). João tinha

\footnotetext{
${ }^{7}$ Esse é um exemplo estruturalmente idêntico ao exemplo do agente que confunde gin com gasolina discutido por Williams $(1981,102)$.
} 
um desejo de beber o café trazido pela garçonete, mas como esse desejo é dependente da crença falsa de que o café não continha açúcar, ele não fornece uma razão. Ou, João não tinha uma razão para beber o café porque que ele acreditava falsamente que bebendo aquela xícara ele iria satisfazer o seu desejo de beber um café sem açúcar.

Quando crenças factualmente falsas estão em jogo há duas possibilidades: (i) João pode acreditar que ele tem razão para fazer, e estar disposto a fazer, o que ele não tem razão para fazer, e (ii) João pode não saber que ele tem razão para fazer o que ele tem razão para fazer. (i) é o que ocorre no caso do café. (ii) pode ocorrer em dois tipos de circunstâncias. Uma é quando João é mal informado ou ignorante de algum fato relevante. Suponha que João seja um grande fã de Star Wars e que para o seu desconhecimento agora está passando o Episódio VI, o seu preferido, no canal 39. Intuitivamente nós diríamos que esse fato é uma razão para ele ligar a televisão no canal 39. Mas como ele é ignorante desse fato, ele não sabe que tem essa razão, e como resultado não está disposto a ligar no canal 39 - ele está disposto a ligar no canal 40, que para o seu conhecimento está passando o Episódio I que ele, como fã de Star Wars, julga muito inferior ao VI.

Williams também admite outra possibilidade: João pode não saber que tem razão para fazer o que ele tem razão para fazer quando ele é ignorante de algum elemento no seu conjunto motivacional que seria promovido pela realização da ação em questão (WILLIAMS 1989, 103). O resultado dessas possibilidades, que Williams destaca como importante considerando que enunciados de razões são enunciados normativos, é uma caracterização negativa do que é um enunciado de razões: um enunciado de que João 
tem uma razão para fazer $\phi$ não é o enunciado de que João está presentemente disposto a fazer $\phi$. Consequentemente, pode ser verdadeiro que João tem uma razão para fazer $\phi$ mesmo se João não tem nenhuma motivação efetiva para fazer $\phi$, ou tem uma motivação efetiva para fazer outra ação. João tem razão para fazer $\phi$ se a realização de $\phi$ por parte de João promover algum elemento no conjunto motivacional de João, exceto nos casos em que a existência desse elemento é dependente de crenças factualmente falsas ou má informação (ignorância de fatos relevantes). Embora (1) pudesse ser assim qualificada, em escritos posteriores ao "Internal and External Reasons" Williams prefere adotar outro tipo de formulação. Considere a segunda, apresentada em "Internal Reasons and the Obscurity of Blame" (a cito com adaptações para o caso do café):

Condição internista (2): João tem uma razão para beber o café trazido pela garçonete somente se ele poderia alcançar a conclusão para beber o café através de uma rota deliberativa correta ${ }^{8}$ que parte das motivações que ele tem .

Ao contrário de (1), (2) univocamente implica que João não tem uma razão para beber o café trazido pela garçonete. A ideia é que, estivesse João seguindo uma rota deliberativa correta a partir dos elementos no seu conjunto motivacio-

\footnotetext{
${ }^{8}$ É difícil reproduzir em português o sentido que Williams pretende ao usar a palavra "sound". Eu optei por traduzir por deliberação "correta" (ao invés de outras possibilidades como "sólida", "apropriada", "adequada" etc) em virtude do fato de que Williams usa como sinônimo de "sound deliberation" expressões como "aright" $(1981,109)$, "deliberated correctly" e "correct deliberator" (1995b, 186-188). O ponto fundamental é entender por "deliberação correta" uma deliberação que corrige apenas erros de fato e raciocínio (1995a, 35). As duas últimas seções do presente artigo serão dedicadas ao problema de analisar duas interpretações diferentes para a ideia de deliberação "correta": uma interpretação procedimental, defendida por Williams, e uma interpretação substantiva, defendida por autores externistas.

9 "A has reason to $\phi$ only if he could reach the conclusion to $\phi$ by a sound deliberative route from the motivations he already has" (WILLIAMS 1995a, 35).
} 
nal, ele chegaria à conclusão de que não tem uma razão para beber o café. Nós podemos dizer que é verdadeiro que ele chegaria a essa conclusão porque uma deliberação correta é tal que ela corrige crenças falsas e a desinformação de fatos relevantes, e, dado o seu desejo de preservar a saúde, se ele estivesse deliberando corretamente nada o atrapalharia de concluir que não tem nenhuma razão para beber o café com açúcar. $\mathrm{O}$ mesmo tipo de explicação poderia ser oferecido para explicar como ele acreditaria que tem uma razão para ligar a televisão no canal 39.

Considere agora a terceira e a quarta formulação da condição internista, oferecidas respectivamente em "Replies" e "Postscript: Some Further Notes on Internal and External Reasons" (assim como antes faço adaptações para o caso de João):

Condição internista (3): Se Maria pode dizer verdadeiramente de João que ele tem uma razão para beber o café, então tem de haver uma rota deliberativa correta em favor da realização dessa ação que parte das motivações existentes de João ${ }^{10}$.

Condição internista (4): João tem uma razão para beber o café somente se há uma rota deliberativa correta que parte do conjunto motivacional de João em favor da realização dessa ação ${ }^{11}$.

(3) e (4) diferem de (2) no seguinte sentido: (2) exige que João seja capaz de seguir a deliberação correta e alcançar, em deliberação, a conclusão de que um fato conta como uma razão em favor da ação, enquanto que (3) e (4) apenas exigem que essa rota deliberativa exista, sem ser ne-

\footnotetext{
10 "If B can say truly of A that A has a reason to $\phi$, then (leaving aside the qualifications needed because of it may not be his strongest reason) there must be a sound deliberative route to $\phi$-ing which starts from A's existing motivations" (WILLIAMS 1995b, 186).

11 "A has a reason to $\phi$ only if there is a sound deliberative route from A's subjective motivational set to A's $\phi$-ing" (WILLIAMS 2001, 91).
} 
cessário que João seja capaz de segui-la ${ }^{12}$. A consequência é que (2) tem implicações diferentes sobre o que João tem razão para fazer. Imagine que João seja uma pessoa socialmente insensível - uma pessoa inconveniente, alguém que "não se toca" - mas que, não obstante essa insensibilidade, nutre o sincero desejo de ser um bom anfitrião ${ }^{13}$. Por culpa da sua insensibilidade, João é incapaz de reconhecer que o seu comportamento acaba deixando os seus convidados extremamente desconfortáveis e, consequentemente, não percebe que deve mudar o seu comportamento se quiser ser de fato um bom anfitrião. João tem razão para mudar o seu comportamento, de acordo com (3) e (4)? A resposta parece positiva. Há uma rota deliberativa adequada que parte do seu desejo de ser um bom anfitrião para a conclusão de que o fato de que o seu comportamento deixa os seus convidados desconfortáveis é uma razão para alterálo. Mas João não pode reconhecer que esse fato é uma razão em deliberação, pois ele é insensível - a sua insensibilidade é justamente uma incapacidade deliberativa de perceber que o seu atual comportamento deixa os seus convidados desconfortáveis. (2) exige que João seja capaz de seguir a rota deliberativa, implicando que esse fato não é uma razão para ele.

Além de revelar que (4) é a sua formulação preferida (WILLIAMS 2001, 91), Williams explicitamente esclarece que o internismo não requer que o agente de fato seja capaz

\footnotetext{
${ }^{12}$ (3) também se diferencia das demais por se tratar de um contexto em que um agente atribui razões a outro. Williams acredita que uma razão que nós podemos atribuir a um agente em terceira pessoa é uma razão que o agente poderia reconhecer em deliberação (WILLIAMS 1981, 103). Esse aspecto da sua posição é discutido na seção 4 deste artigo.

${ }^{13}$ Exemplos que estipulam agentes com incapacidades deliberativas não são incomuns na literatura sobre o internismo de razões (por exemplo, ver Millgram, 1996). O particular exemplo do anfitrião insensível que eu adoto é elaborado por Scanlon $(1998,366)$.
} 
de empreender a deliberação correta (WILLIAMS 1995b, 188). Contudo, o argumento de Williams em favor da condição internista, como será aludido na segunda parte deste ensaio, parece mais coerente com (2).

\section{AS DIMENSÕES EXPLANATÓRIA E DELIBERATIVA}

O que leva Williams a propor a condição internista, relativizando o que João tem razão para fazer ao que ele poderia estar motivado a fazer após deliberação correta? Em um sentido que será explorado ao longo deste ensaio, a motivação essencial para a condição internista é aceitação da tese de que se o fato de que o prédio está em chamas é uma razão para João, então João tem de ser capaz de adquirir a motivação para efetivamente sair do prédio por acreditar que esse fato é uma razão. Quando a condição internista é satisfeita é fácil explicar como o agente que pretensamente tem uma razão para fazer $\phi$ poderia estar motivado a fazer $\phi$, a saber, a realização de $\phi$ satisfaz algum desejo que o agente tem.

Outra maneira de expressar essa mesma motivação é através da interconexão, defendida por Williams, entre razões motivantes e normativas. Essa interconexão é expressa na dimensão explanatória de razões normativas:

Dimensão explanatória, formulação de Williams: se é dito, no modo normativo, que João tem uma razão para fazer $\phi$, tem de se conceber a possibilidade de que João faça $\phi$ por essa razão ${ }^{14}$.

\footnotetext{
${ }^{14}$ Esta é a última formulação oferecida por Williams da dimensão explanatória: "If it is said, in the normative mode, that A has a reason to $\phi$, the speaker must envisage the possibility of A's $\phi$ ing for that reason, in which case the reason will figure in the explanation of what A does" (2001, 93). Há também estas formulações: "If there are reasons for action, it must be that people sometimes act for those reasons, and if they do, their reasons must figure in some correct explanation of their actions" $(1981,102)$, "If something can be a reason for action, then it could be someone's Cont.
} 
Para entender essa dimensão, devemos diferenciar razões motivantes de razões normativas. Considere sentenças do tipo "a tristeza por ter perdido a namorada ontem foi a razão pela qual João decidiu morrer asfixiado, mas essa não era uma razão para ele fazer o que fez". Sentenças desse tipo aparentemente invocam dois sentidos de razão que não são equivalentes. Eis uma explicação possível: quando João faz $\phi$ intencionalmente há um certo estado mental que o levou a fazer $\phi$, ou o que o motivou a fazer $\phi$, ou a partir do qual ele fez $\phi$. Williams segue Davidson em defender que o estado mental que explica ações intencionais é composto por crenças e alguma pró-atitude como um desejo (DAVIDSON 1980, 2-3). Quando citamos as crenças e desejos que levaram João fazer $\phi$ intencionalmente, citamos as razões motivantes pelas quais João fez $\phi$. Nesse sentido, como definido por Smith, razões motivantes são estados psicológicos do agente (SMITH 1994, 96). Nessa sentença acima, o conceito de razão que aparece antes da vírgula é o de razão motivante. No caso em questão, a razão motivante de João pode ser descrita grosseiramente como a sua crença de que o namoro acabou e o seu desejo de não viver sem a sua namorada. Quando fazemos um enunciado sobre as razões (motivantes) pelas quais João fez $\phi$, o objetivo é explicar ou entender o que João viu de favorável na realização de $\phi$ - por isso que algumas vezes razões motivantes são chamadas de razões explanatórias.

Aparentemente não é com explicação e compreensão que estamos preocupados quando dizemos, depois da vírgu-

reason for acting on a particular occasion, and it would then figure in an explanation of that action" $(1981,106)$ e "If it is true that A has a reason to $\phi$, then it must be possible that he should $\phi$ for that reason; and if he does act for that reason, then that reason will be the explanation of his acting" (1995a, 39). 
la, que a tristeza por ter perdido a namorada não é uma razão para João se suicidar. Ao invés, parece que agora a intenção é crítica: estamos dizendo que o fato de que João está triste pelo fim do namoro não conta em favor do suicídio. Razões normativas podem ser entendidas, em uma leitura plausível, como fatos ou considerações verdadeiras que contam em favor ou contra a realização de certas ações. A condição internista é uma condição de adequação para enunciados de razões que empregam o conceito de razão nesse sentido normativo do termo. Williams esclarece que o aspecto normativo de enunciados de razão se deve ao fato de que esses enunciados concernem ao que é racional para o agente fazer (WILLIAMS 1981, 103) ou ao que faz sentido para ele (WILLIAMS 2001, 93). Outro aspecto normativo de razões normativas é o de operar como considerações em conselhos (da forma "se eu fosse você...") sobre o que fazer (WILLIAMS 1995a, 36). Se João perguntasse para qualquer pessoa o que fazer, ele seria aconselhado a sair do prédio pela razão de que o prédio está em chamas. Razões motivantes, pelo que parece, não são aptas para figurar como conselhos.

Em outras formulações da dimensão explanatória Williams escreve que uma razão normativa de João é uma das suas razões motivantes possíveis. Como razões normativas são simples fatos, como o fato de que o prédio está em chamas, e o que pode motivar o indivíduo a agir são crenças e desejos sobre fatos, não os próprios fatos (essa é a tese de Davidson que Williams aceita sobre o que explica ações intencionais), as razões normativas de João não poderiam ser propriamente as suas razões motivantes possíveis. Para fins de precisão penso que deveríamos reformular a dimensão explanatória do seguinte modo: 
Dimensão explanatória, qualificada: se um fato $p$ pode ser uma razão para João fazer $\phi$, então João poderia fazer $\phi$ por acreditar que $p$ é uma razão para fazer $\phi$, e a crença de que $p$ é uma razão para fazer $\phi$ figuraria em uma explanação de por que João fez $\phi$.

O que a dimensão explanatória diz, então, é que o fato de que o prédio está em chamas é uma razão (no modo normativo) para João sair do prédio somente se João for capaz de sair do prédio por acreditar que esse fato é uma razão para sair do prédio. A conexão entre razões normativas e motivantes é esta: quando João acredita que esse fato é uma razão para sair do prédio, a crença nesse fato é a sua razão motivante para agir. É nesse sentido que proponho interpretar a tese de que as razões normativas de João figuram na explanação de uma ação de João.

Nenhum elemento do internismo de razões faz com que a distinção intuitiva e enraizada no senso comum entre razões motivantes e normativas precise ser rejeitada. Williams famosamente defende, no entanto, que é um erro separar esses dois sentidos (WILLIAMS 1995a, 39). Eu gostaria de sugerir que o erro consiste não na distinção conceitual em si, mas em ignorar que quando João reconhece que ele tem uma razão para fazer algo, esse reconhecimento tem de afetar ou explicar o que João passa a ter como razões motivantes, e, portanto, o que ele faz.

Há várias maneiras de João estar motivado a fazer o que ele acredita que tem razão normativa para fazer - por exemplo, João pode ser condicionado para estar motivado a fazer o que ele acredita que tem razão normativa para fazer (esse parece ser o caso com as pessoas que sofrem engenharia genética em Brave New World (1932), de Aldous Huxley). Williams acredita que para um fato p ser uma razão para João fazer $\phi$, João tem de poder fazer $\phi$ por acreditar que $p$ é 
uma razão para fazer $\phi$, mas essa crença tem de poder ser adquirida como resultado da deliberação correta de João (WILLIAMS 1981, 109) - em que, se uma crença é obtida como resultado de manipulação de qualquer tipo, ela não é obtida através de uma deliberação correta. Razões têm assim, além dessa dimensão explanatória, uma dimensão deliberativa. Williams expressa essa ideia quando defende que a razão que atribuímos a João como espectadores em terceira pessoa tem de ser uma razão que João poderia atribuir a si mesmo como resultado de sua deliberação, ou que ele poderia reconhecer como uma razão em deliberação (WILLIAMS 1981, 103). Essa dimensão deliberativa será mais profundamente discutida nas duas últimas seções.

\section{O CONCEITO DE RAZÃO NORMATIVA}

Por conveniência, no restante deste ensaio a expressão "razão interna" será utilizada para designar um enunciado de razões que satisfaz a condição internista - e "razão externa" estará para um enunciado de razões que é (supostamente) verdadeiro mas não satisfaz a condição internista. Essa observação, também feita por Williams, é necessária porque falar em razões internas é confuso e potencialmente enganoso. Creio que Williams não está comprometido com a tese de que razões normativas são internas no sentido de serem estados mentais do agente, ou que elas são criadas pelos desejos de agente ou que esses desejos são fontes de razões ${ }^{15}$. Note que em um dos exemplos analisados por Williams, o do marido que não vê razões para tratar bem a sua esposa, o interlocutor imaginado insiste para o marido que

\footnotetext{
${ }^{15}$ Este é um ponto enfatizado por Dancy $(2000,18)$.
} 
ele deve tratá-la bem porque ela é sua esposa - o fato de que ela é sua esposa é a sua razão para tratá-la bem ${ }^{16}$. Semelhantemente, no exemplo de Owen Wingrave a família argumenta que o fato de que todos os homens da família serviram ao exército, e que essa é uma tradição familiar, é uma razão para Owen servir ao exército (WILLIAMS 1981, 106).

Assim, a razão para João sair do prédio é o fato de que o prédio está em chamas e que ele morrerá asfixiado se permanecer nele, e não o seu desejo de não morrer asfixiado. O que há de "interno", se quisermos insistir na terminologia, são os elementos que fazem parte da explicação de por que certos fatos contam como razões para João ${ }^{17}$. O desejo de João de não morrer asfixiado é o que faz verdadeiro enunciar de João que ele tem uma razão para sair do prédio, e explica por que o fato de que o prédio está em chamas é uma razão para João. Esses elementos, enquanto parte do conjunto motivacional de João, são internos - são parte da sua "psicologia" (WILLIAMS 1995b, 191) ${ }^{18}$ - mas razões, enquanto fatos, são externas à sua psicologia ${ }^{19}$.

\footnotetext{
16 "Suppose, for instance, I think someone (I use 'ought' in an unspecific way here) ought to be nicer to his wife. I say, 'You have a reason to be nicer to her'. He says, 'What reason?' I say, 'Because she is your wife." (WILLIAMS 1995a, 39). Algumas vezes Williams de fato sugere que razões são elementos no conjunto motivacional do agente, por exemplo quando ele afirma que se a razão é uma explanação da ação do agente, então ela estará "de alguma forma" no seu conjunto motivacional (WILLIAMS 1995a, 39). O "de alguma forma" torna a afirmação ambígua, mas, penso, sugere que para ele a razão não está literalmente no seu conjunto motivacional.

${ }^{17}$ A importância de se distinguir entre razões e suas condições de fundo é especialmente defendida por Schroeder $(2007,37)$.

${ }^{18}$ Williams 1995b, 191.

${ }^{19}$ Algumas vezes razões podem ser estados mentais, e quando isso ocorre razões normativas são genuinamente "internas". Por exemplo, alguém pode dizer que o fato de que João tem um desejo compulsivo para roubar objetos insignificantes é uma razão para ele procurar ajuda profissional. O que se nega ao afirmar que razões são internas é a tese de que a razão de João para procurar ajuda profissional é a sua crença de que tem um desejo compulsivo para roubar objetos insignificantes e/ou o seu desejo de não ter o desejo de roubar objetos insignificantes. Essas crenças e esse desejo de segunda-ordem são condições que explicam por que o fato de que João tem um desejo Cont.
} 


\section{O ARGUMENTO EM FAVOR DA CONDIÇÃO INTERNISTA}

Não é exatamente claro qual argumento Williams teria oferecido em favor da condição internista ${ }^{20}$. Eu gostaria de sugerir que devemos considerar seriamente o que Williams menciona, em "Internal Reasons and the Obscurity of Blame”, como as duas motivações para o internismo de razões (WILLIAMS 1995a, 38-39). A primeira é a interrelação entre razões explanatórias e razões normativas, conforme vista a pouco. A segunda, que é em larga medida um desdobramento da primeira, e é mais difícil de ser sumarizada, eu proponho entender do seguinte modo: a alternativa ao internismo (o externismo) não oferece um critério nãocircular para julgar quando enunciados de razões são “apropriados”. Nesta seção eu gostaria de analisar a primeira motivação. A segunda motivação será de interesse na discussão do conceito de deliberação correta na seção seguinte.

A primeira motivação parece dar origem ao seguinte argumento em favor da condição internista:

P1. O fato $p$ é uma razão para João fazer $\phi$ somente se João pode fazer $\phi$ por acreditar como resultado de deliberar corretamente que $p$ conta em favor da realização de $\phi$.

P2. João apenas pode fazer $\phi$ por acreditar como resultado de deliberar corretamente que $p$ conta em favor da realização de $\phi$ se houver algum elemento no seu conjunto motivacional a partir do qual ele poderia

\footnotetext{
compulsivo para roubar objetos insignificantes é uma razão para ele procurar ajuda profissional, mas eles não são, conforme interpreto Williams, as razões normativas de João.

${ }^{20}$ Ver Finlay (2010) para uma análise de várias interpretações do argumento de Williams.
} 
deliberar para concluir que $p$ conta em favor da realização de $\phi$.

C. p é uma razão para João fazer $\phi$ somente se há uma rota deliberativa adequada que parte do conjunto motivacional de João para a realização de $\phi$.

Nós podemos entender o argumento acima considerando a objeção de Williams contra a existência de razões externas. Considere uma nova situação para João. João está em uma lancheria decidindo o que pedir. Ele decide, sob protestos de sua amiga Maria, pedir um pastel de camarão. Maria sustenta que o sofrimento dos animais quando eles são abatidos é uma razão para João deixar de comer carne e pedir um pastel de espinafre. João, porém, foi criado em uma comunidade de pescadores a vida inteira, é uma tradição local pescar para consumo, ele odeia o sabor de fontes vegetais de proteína - especialmente espinafre - e acredita que animais não têm direitos morais. Não há nada em seu conjunto motivacional que poderia o levar via deliberação à conclusão de que o fato de que os animais sofrem quando são abatidos é uma razão para pedir um pastel de espinafre. Se a despeito disso se afirma que é verdadeiro que o fato de que os animais sofrem quando são abatidos é uma razão João para pedir um pastel de espinafre, então essa razão tem de ser "externa" não seria falsificado pela ausência de um elemento no conjunto motivacional de João que poderia levá-lo a reconhecêlo via deliberação como um enunciado verdadeiro.

$\mathrm{O}$ argumento de Williams contra razões externas co-

\footnotetext{
${ }^{21}$ Esse exemplo é estruturalmente idêntico ao de Owen Wingrave discutido por Williams (1981, 106).
} 
meça observando que Maria, ao tentar explicar por que o enunciado "o fato de que os animais sofrem quando são abatidos é uma razão para João pedir um pastel de espinafre" é um enunciado verdadeiro sobre as razões de João, levará em conta a dimensão explanatória de razões afirmada em P1. Isso significa que Maria acredita que João pode vir a pedir um pastel de espinafre por acreditar que o fato de que os animais sofrem quando são abatidos é uma razão deixar de pedir um pastel de camarão. Williams também assume que uma externista como Maria aceita a dimensão deliberativa, aceitando que João adquiriria a motivação para pedir o pastel de espinafre se deliberasse corretamente sobre as suas razões $^{22}$. Isso significa que tanto para o internista quanto para o externista a verdade da sentença (A) "João tem uma razão pedir um pastel de espinafre” implica na verdade de $(\mathrm{B})^{23}$ :

(B) Se João deliberasse corretamente ele adquiriria a motivação para pedir um pastel de espinafre.

$\mathrm{O}$ que distingue o externismo de Maria do internismo de Williams é que Maria acredita que João viria a ter essa motivação independentemente do que está no seu conjunto motivacional antes do início do processo deliberativo. Maria aceita $\mathrm{P} 1$, mas não $\mathrm{P} 2$.

$\mathrm{O}$ que o externista precisa, dado o seu comprometimento a P1, é mostrar como João pode, como resultado de deliberar corretamente, vir a adquirir a motivação para pe-

\footnotetext{
22 "External reasons theorist essentially wants, that the agent should acquire the motivation because he comes to believe the reason statement, and that he should do the latter, moreover, because, in some way, he is considering the matter aright" (WILLIAMS 1981, 109)

23 "The external reasons statement itself will have to be taken as roughly equivalent to, or at least as entailing, the claim that if the agent rationally deliberated, then, whatever motivations he originally had, he would come to be motivated to $\phi "$ (WILLIAMS 1981, 109).
} 
dir um pastel de espinafre, e vir a adquirir a crença de que o fato de que os animais sofrem quando são abatidos é uma razão para pedir pastel de espinafre, independentemente do que está no seu conjunto motivacional antes da deliberação. Em outras palavras, o externista precisa então oferecer uma explicação de como (A) pode implicar (B) sem contar com P2. O ponto básico de Williams contra a possibilidade de razões externas é defender que tal explicação não existe (WILLIAMS 1981, 109).

Se João delibera cuidadosamente e corrige os erros de fatos envolvidos nas suas crenças - e se ele também realiza inferência adequadas a partir da suas crenças etc -, mas não adquire a motivação para pedir um pastel de espinafre, o internista afirma então que (B) é falsa, pois João deliberou corretamente e não alcançou a conclusão de que o fato de que os animais sofrem quando são abatidos é uma razão para pedir um pastel de espinafre. $O$ cerne da objeção de Williams ao externismo consiste em negar que (B) possa se obter quando não há algo no conjunto motivacional de João que poderia levá-lo via deliberação à conclusão de que um fato é uma razão para fazer algo. $\mathrm{O}$ argumento é de que não pode se obter porque toda a deliberação correta - ou racional - tem de partir de algum elemento no conjunto motivacional do agente. Se João deliberar corretamente, ele chegará à conclusão de que nenhum elemento no seu conjunto motivacional o autoriza a concluir que o fato de que os animais sofrem quando são abatidos é uma razão para pedir pastel de espinafre. Como razões externas são por definição razões de João que não estão relacionadas com nenhum elemento do seu conjunto motivacional, elas não podem explicar a conduta de João de um modo que satisfaça a dimensão explanatória e deliberativa: João não pode 
pedir um pastel de espinafre por acreditar que esse fato é uma razão como resultado de deliberar corretamente ${ }^{24}$.

\section{A CONCEPÇÃO PROCEDIMENTAL DE DELIBERAÇÃO CORRETA}

Como se pode notar, o argumento acima depende crucialmente de uma certa concepção de deliberação correta. Nesta seção eu gostaria de discutir a seguinte objeção ao argumento de Williams: P2 apenas é necessária para explicar P1 se se assume uma certa concepção procedimental de deliberação correta como verdadeira. Como Williams não defende essa concepção, e apenas a assume como verdadeira, o seu argumento é impotente contra posições externistas que além de rejeitar a condição internista também rejeitam uma concepção procedimental de deliberação correta ${ }^{25}$. No que se segue eu apresentarei a distinção entre uma concepção procedimental e uma concepção substantiva e em que medida o internismo de razões precisa contar com uma concepção procedimental.

Teóricos externistas podem concordar que o que João tem razão para fazer é o que ele estaria motivado a fazer se deliberasse corretamente - isto é, se ele possuísse as crenças e os desejos resultados de uma deliberação correta -, mas podem defender que disso não se segue, como Williams alega no movimento de P1 para P2, que o que João tem razão para fazer depende dos elementos do seu conjunto

\footnotetext{
${ }^{24}$ É comum interpretar o argumento de Williams como partindo de uma concepção humeana de motivação moral - por exemplo, ver Korsgaard (1996). Williams, contudo, concede ao externista que a mera crença de que um enunciado de razão externa é verdadeiro pode explicar ações (WILLIAMS 1981, 106-107), o que é incompatível com uma leitura humeana.

${ }^{25}$ McDowell (1996) e Hooker (1987).
} 
motivacional. Considere como Maria poderia insistir que João tem razão para pedir um pastel de espinafre, a despeito de não haver no conjunto motivacional de João nenhum elemento que poderia levá-lo via deliberação à conclusão de que ele tem essa razão. Maria pode argumentar que ele tem razão para pedir um pastel de espinafre porque a sua falha em adquirir a motivação é um caso de deliberação incorreta. Note que de acordo com o raciocínio de Maria, a sentença (A) "João tem uma razão para fazer $\phi$ " realmente implica (B) "Se deliberasse corretamente João estaria motivado a fazer $\phi$ " (B), mas (B) significa algo que implica (C):

(C) João delibera corretamente quando ele adquire motivação para fazer o que ele tem razão para fazer.

(C) é o tipo de explicação do que significa deliberar corretamente que o próprio Parfit oferece em favor da sua teoria externista de razões baseada em valores (PARFIT 2011, 62). Em uma nomenclatura proposta por Parfit, nós devemos classificar concepções de deliberação correta e de agente racional como a sua como concepções substantivas. Concepções substantivas estipulam certos fins ou desejos, e certas considerações morais e prudenciais (preocupação com o bem-estar dos animais, por exemplo), como parte da ideia de um agente (substantivamente) racional. Maria pode argumentar que devido a deficiências no conjunto motivacional de João ele não está em posição de adquirir, como resultado da sua deliberação, a motivação para fazer o que ele tem razão (externa) para fazer - em outras palavras, ele não está em posição de deliberar corretamente ${ }^{26}$.

\footnotetext{
${ }^{26}$ Considere como McDowell responde à objeção de Williams ao externista: "There is no implication, as in Williams' argument, that there must be a deliberative or rational procedure that would lead anyone from not being so motivated to being so motivated. On the contrary, the transition Cont.
} 
Concepções substantivas de racionalidade são diferentes de concepções procedimentais. Concepções procedimentais não estipulam o reconhecimento de alguma consideração prudencial ou moral como requerimento de racionalidade. Elas propõem que é suficiente para que um agente seja considerado racional, e que a sua deliberação seja considerada correta, que ele tenha corrigido erros de raciocínio como inconsistências e incoerências entre os elementos do seu conjunto motivacional - bem como, podemos supor, ele não tenha violado certas regras formais de inferência como modus ponens e modus tollens -, e se ele tenha corrigido erros de fato e ignorância presentes no seu sistema de crenças, abandonado os desejos que dependem dessas crenças etc. Esses requerimentos são procedimentais, e não substantivos, no sentido de que eles apenas exigem que o agente tenha uma certa combinação de desejos e crenças, mas não requerem que essas crenças tenham um conteúdo particular ou que os desejos tenham um objeto particular.

Se Williams permitir que o externista interprete o conceito de deliberação correta substantivamente, então o seu argumento é impotente para negar a tese de que João tem razões externas para agir ${ }^{27}$. Uma concepção procedimental, por outro lado, não é impotente porque para ela o resultado de uma deliberação correta é uma função dos pontos de partida da reflexão - diferentes indivíduos, com diferentes pontos de partida, obterão conclusões diferentes ${ }^{28}$. Maria

\footnotetext{
to being so motivated is a transition to deliberating correctly, not one effect by deliberating correctly" (MCDOWELL 1995, 78).

${ }^{27}$ Como notado por McDowell $(1995,79)$.

${ }^{28}$ Para análise de diferenças concepções procedimentais, incluindo a de Williams, ver Hooker e Streumer (2004).
} 
não pode argumentar que a deliberação de João foi proceduralmente incorreta.

É incontroverso interpretar Williams como oferecendo uma concepção procedimental de deliberação $\operatorname{correta}^{29}$, e ele insiste em não estipular o reconhecimento de considerações morais e prudenciais como parte do significado de deliberar corretamente. O seu raciocínio é o de que caso esse reconhecimento fosse exigido deixaria de haver qualquer diferença significativa entre posições internistas e externistas (WILLIAMS 1995a, 36). Mas se o conceito de deliberação correta empregado pelo internismo de razões é procedimental, então ele parece resultar em um argumento que é inconvincente, pois o externista não apenas rejeita a condição internista, mas também a concepção procedimental. O internismo de razões apenas é preferível ao externismo se houver algum argumento suplementar em favor de uma concepção procedimental, e muitos objetam a posição de Williams reclamando que ele não apresenta tal argumento.

\section{O ARGUMENTO EM FAVOR DE UMA CONCEPÇÃO PROCEDIMENTAL}

Creio que Williams, embora não empregue as nomenclaturas procedimental e substantivo, estava ciente desse problema e de fato se antecipou a ela oferecendo um argumento em favor de uma concepção procedimental ${ }^{30}$.

\footnotetext{
${ }^{29}$ Parfit (2007), Smith (2009), Hooker e Streumer (2004), Markovits (2014).

${ }^{30}$ Considere esta passagem em que Williams reconhece a objeção: "The force of an external reason statement can be explained in the following way. Such a statement implies that a rational agent would be motivated to act appropriately, and it can carry this implication because a rational agent is precisely one who has a general disposition... to do what (he believes) there is reason for him to do" (WILLIAMS 1981, 109).
} 
Williams apresenta o internismo de razões como uma teoria sobre o sentido de enunciados do tipo (A). Ela propõe que quando dizemos (A), o que queremos dizer é (B), ou algo que implique (B). Se o conceito de deliberação correta é interpretado substantivamente, como defendido pelo externista, (B) implica (C): João delibera corretamente quando ele adquire motivação para fazer o que ele tem razão para fazer. Se (B) implica (C), (B) não serve para esclarecer o conteúdo de $(A)$ porque $(C)$ emprega justamente o conceito de razão de (A) que (B) deveria estar esclarecendo.

Eis o que seria, penso, o argumento de Williams: enunciados de razão externa são "obscuros" porque o externista não oferece um critério não-circular para distinguir enunciados de razões verdadeiros de enunciados falsos ${ }^{31}$. Williams aceita que entender o sentido ou significado de uma sentença é o mesmo que compreender as suas condições de verdade $^{32}$. A consequência do raciocínio acima, então, é que o externista é incapaz de explicar sob que condições um enunciado de razão externa é apropriado ou verdadeiro ${ }^{33}$. $O$ internista explica que $(A)$ é verdadeiro quando $(B)$ é verdadeiro, e (B) é verdadeiro quando há no conjunto

\footnotetext{
${ }^{31}$ Esse argumento de Williams pressupõe que enunciados normativos da forma "S tem uma razão para $\phi$ " podem ser de alguma forma ser explicados por enunciados que não empregam o conceito de razão, como o enunciado de que "S estaria motivado a fazer $\phi$ se deliberasse corretamente". Muitos externistas negam que enunciados de razão possam ser explicados dessa forma (PARFIT 1997; SKORUPSKI 2010, 252; SCANLON 2014, 2). Para esses autores o argumento de Williams em favor de uma concepção procedimental é inconvincente.

32 "What are the truth conditions for statements of the form 'A has a reason to $\phi$ ', where A is a person and ' $\phi$ ' is some verb of action? What are we saying when we say someone has a reason to do something?" (WILLIAMS 1995a, 35).

33 "One of the mysterious things about the denial of internalism lies precisely in the fact that it leaves it quite obscure when this form of words is thought to be appropriate. But if it is thought to be appropriate, what is supposed to make it appropriate, as opposed to (or in addition to) all those other things that may be said?" (WILLIAMS 1995a, 39-40).
} 
motivacional de João algum elemento a partir do qual João poderia deliberar para concluir que (A). Esses elementos são as condições de verdade de um enunciado como (A), e eles não empregam o conceito de razão que figura em (A). Mas como avaliar se (A) é verdadeiro, quando a razão em questão é externa? Se João delibera e não adquire a motivação para fazer o que ele tem razão externa para fazer, o externista pode se defender argumentando que João ainda não deliberou corretamente e por isso não adquiriu a motivação. Mas por que essa afirmação seria verdadeira? Ela parece pressupor a verdade da proposição de que João tem essa razão para fazer $\phi$, justamente o que está em questão (WILLIAMS 1981, 109-110).

Quando Williams rejeita posições externistas, ele identifica algo de suspeito em um enunciado de razão externa: o externista pode afirmar o que ele quiser. É nesse sentido, eu sugiro, que devemos interpretar a afirmação de Williams de que uma atribuição de razão externa não passa de um "blefe" (WILLIAMS 1981, 111).

\section{CONSIDERAÇÕES FINAIS}

O meu objetivo neste artigo foi o de caracterizar o internismo de razões como uma explicação sobre por que certos fatos contam como razões para alguém fazer algo, e então esclarecer os conceitos envolvidos nessa explicação, o argumento oferecido em favor dela e a concepção procedimental de deliberação correta subjacente. Eu gostaria de sumarizar dois resultados que eu espero ter obtido, se o que foi defendido está correto. O primeiro é o de ter identificado que o real foco de controvérsia entre Williams e seus críticos concerne à seguinte questão: devemos interpretar o 
conceito de deliberação correta procedimentalmente, como Williams propõe, ou substantivamente, como externistas defendem? O segundo resultado é o de ter mostrado que Williams não apenas estava ciente dessa questão, como ofereceu um argumento em defesa da sua preferência por uma concepção procedimental. De acordo com esse argumento, uma concepção procedimental é a única capaz de oferecer uma solução não-circular para o problema de distinguir enunciados de razões verdadeiros de enunciados de razões falsos. Assim, é falso afirmar que Williams assume a verdade de uma concepção procedimental, ou que ele não considera seriamente a viabilidade de uma concepção alternativa.

Abstract: The aim of this article is to discuss Bernard Williams's theory of reasons for action. Following the introduction and analysis of its main concepts (internalist condition, explanatory and deliberative dimensions, normative reasons) and the identification of the argument that it is offered in its favor and against alternative positions, I analyze the objection that the soundness of this argument depends on the acceptance of a procedural conception of correct deliberation that Williams would have assumed, without offering any argument, as true. I argue that this objection is false because it is possible to identify in his writings a supplementary argument justifying his preference for a procedural conception.

Keywords: Reasons; Explanatory Dimension; Deliberative Dimension; Procedural Conception.

\section{REFERÊNCIAS}

DANCY, Jonathan. Practical Reality. Oxford: Oxford University Press, 2000.

DAVIDSON, Donald. "Actions, Reasons, and Causes" (1963). Republicado em: DAVIDSON, Donald. Essays on Actions and Events. Oxford: Oxford Clarendon Press, 1980: 3-19. 
FINLAY, Stephen. "The Obscurity of Internal Reasons". Philosophers' Imprint, 9 (7), p.1-22, 2009.

HOOKER, Brad. "Williams' Argument Against External Reasons”. Analysis, 47 (1), p.42-44, 1987.

HOOKER, Brad; STREUMER, Bart. "Procedural and Substantive Practical Rationality". In: MELE, Alfred; RAWLING, Piers (eds.). The Oxford Handbook of Rationality. Oxford: Oxford University Press, 2004, p.57-74.

KORSGAARD, Christine. "Skepticism about Practical Reason" (originalmente publicado em 1986). Republicado em: KORSGAARD, Chrstine. Creating the Kingdom of Ends. Cambridge: Cambridge University Press, 1996, p.311-334.

MARKOVITS, Julia. Moral Reason. Oxford: Oxford University Press, 2014.

MCDOWELL, John. "Might There Be External Reasons?". In: ALTHAM, J.E.J; HARRISON, R (eds.). World, Mind and Ethics: Essays on the Ethical Philosophy of Bernard Williams. Cambridge: Cambridge University Press, 1995, p.6885.

MILLGRAM, Elijah. "Williams' Argument Against External Reasons”. Noûs, 30 (2), p.197-220, 1996.

PARFIT, Derek. On What Matters. Volume One. Oxford: Oxford University Press, 2011.

- "Reason and Motivation". Proceedings of the Aristotelian Society, Supplementary Volume 71, p.99-13, 1997.

SCANLON, Thomas. Being Realistic about Reasons. Ox- 
ford: Oxford University Press, 2014.

. What We Owe to Each Other. Cambridge: Harvard University Press, 1998.

SCHROEDER, Mark. Slaves of the Passions. New York: Oxford University Press, 2007.

SKORUPSKI, John. The Domain of Reasons. Oxford: Oxford University Press, 2010.

SMITH, Michael. "Desires, Values, Reasons, and the Dualism of Practical Reason". In: SUIKKANE, J; COTTINGHAM, J. Essays On Derek Parfit's On What Matters. Oxford: Blackwell Publishing, 2009, p.116-143.

. The Moral Problem. Oxford: Blackwell Publishing, 1994.

WILLIAMS, Bernard. Ethics and the Limits of Philosophy. Cambridge: Harvard University Press, 1985.

. "Internal and External Reasons" (1981). Republicado em WILLIAMS, Bernard. Moral Luck. Cambridge: Cambridge University Press, 1981, p.101-113.

. "Internal Reasons and the Obscurity of Blame" (1989). Republicado em: WILLIAMS, Bernard. Making Sense of Humanity, and other Philosophical Papers. Cambridge: Cambridge University Press, 1995a, p.35-45.

, 2001. "Postscript: Some Further Notes on Internal and External Reasons". In: MILLGRAM, Elijah (ed.). Varieties of Practical Reasoning. Cambridge: MIT Press, 2001, p.91-7. 
. "Replies". In: ALTHAM, J.E.J; HARRISON, R (eds.). World, Mind and Ethics: Essays on the Ethical Philosophy of Bernard Williams. Cambridge: Cambridge University Press, 1995b, p.185-224. 